\section{Parques Temáticos}

\section{RESUMO}

O mundo contemporâneo globalizou-se, destruiu fronteiras, tornou o impossivel de ontem no possivel de hoje. Aproximou distâncias, desenvolveu tecnologia, informação e um novo conceito de divertimento e lazer em família, em grupos ou até mesmo individual. Entre as novas propostas estão os parques temáticos.

\section{ABSTRACT}

Nowadays, there is a new concept of entertainment and leisure. Within this context, there are many alternatives, the theme park being one of the most important. This article discusses this option of leisure.

\section{MARY SANDRA G. ASHTON}

Mestranda em Comunicação Social - FAMECOS/PUCRS

\section{Inłrodução}

O CONTEÚDO QUE apresentaremos neste trabalho é resultado de uma pesquisa que arrolou muitas informações sobre vários aspectos dos parques temáticos, sempre com o foco centrado na história e no resgate cultural na era pós-moderna. Os parques temáticos representam, hoje, uma proposta de pesquisa multifacetada, ligada ao Turismo, à economia, sociologia, história, geografia, e tantas outras áreas.

A pesquisa aqui apresentada pretende, em sua essência, ser um instrumento de abertura ao debate, buscando introduzir perguntas e possíveis respostas, sobre o conceito e histórico dos parques temáticos; sua origem, sua finalidade e por quem foram criados, além de outras questões que provavelmente aparecerão ao longo da leitura. As respostas foram buscadas em autores que tem se aproximado do tema quer em livros, quer na imprensa, quer via textos na internet.

Suas idéias e propostas teóricas serão confrontadas com um estudo de caso, do "Mini Mundo" que é um parque temático de contemplação, de propriedade particular, localizado na cidade de Gramado, no Rio Grande do Sul, bem como o resgate de sua história, uma atividade que foi preservada e vem passando de geração em geração, conservando as características propostas por seu criador.

A conclusão tem como objetivo situar o leitor e contribuir para a reflexão e posterior debate das teorias aqui apresentadas. É apresentado o caso brasileiro, estudando o seu desenvolvimento acelerado nos últimos anos.

\section{Parques Temáticos}

\subsection{Conceito}

Edward Soja (1996), em sua pesquisa 
intitulada Parques Temáticos - Contextualização Existencial, afirma que "parques temáticos são híbridos contemporâneos que como a maioria dos fenômenos pós-modernos - cruzam as fronteiras que normalmente separam os até então distintos reinos da cultura, da economia, da filosofia, da sociologia e da política". Ele explica que:

“os parques temáticos equivalem-se a modelos mutantes que servem como laboratórios civilizacionais que têm sua arquitetura limitada à simbologia e à estética, possível apenas como uma experiência isolada e bem definida. O paradoxo é que paralelamente à complexidade cultural programática e à instabilidade da civilização contemporânea, os parques temáticos oferecem às pessoas a oportunidade de retornar a um iconicismo eclético, a uma clareza formal e, sobretudo, à narrativa da vida em sociedade, marcando o retorno a uma posição fortemente contrária aos dogmas antirepresentacionais cíclicos governados pelos modernismos atuais. Os parques públicos e jardins imperiais do passado, são considerados ancestrais dos parques temáticos por terem sido concebidos como espaços complexos de representação simbólica da cultura e da sociedade."

Para o autor, os parques temáticos contemporâneos figuram como "espelhos universais" que oferecem imagens da consciência coletiva normalmente difusos ou perdidos, permitindo ao observador reconstruir e reencontrar seu lugar no universo.

Ao afirmar que parques temáticos são fenômenos pós-modernos, Soja provavelmente refere-se ao "pós-modernismo consumista" em que a arte e a vida se fundem, são congeladas e transferidas ou emprestadas à outro espaço, a fim de serem contempladas, vivenciadas e consumidas por visitantes das mais diversas origens.
No que diz respeito à arquitetura, argumenta-se que o estilo mais aceito para projetos de parques temáticos tenha sido o pós-moderno, caracterizado por certa liberdade formal e por conter elementos facilmente aceitos e adaptáveis. Ao adotar um tema, o parque se apropria de sua simbologia e restringe-se a representá-la como forma de reviver ou retroceder no tempo e no espaço ou ainda buscar algo no futuro (matar parte da sua curiosidade em relação ao mesmo). Sem dúvida, os parques da Disney são ícones do pós moderno, já que comemoram orgulhosamente as cópias de elementos anteriores da alta cultura que, produzidos em massa, não significam mais o que quer que seja em particular, mas sim uma hiper-realidade, onde a simulação visual e auditiva são mais reais do que o original que as inspirou, com uma arquitetura de superfícies e de aparências, onde o real já foi transformado, melhorado, a fim de ser consumido. É o que Debord (apud Urry, 1996: 196) descreve como "sociedade do espetáculo" em que as representações se aproximam mais de nossas expectativas em relação à realidade, dos signos que carregamos e que esperamos serem desencadeados. "Os espetáculos visuais nos mostram uma natureza falsificada que correspondem muito mais as nossas exigências e devaneios... a tecnologia pode nos proporcionar mais realidade do que a natureza", (Eco,1986: 44).

Sem dúvida, os parques temáticos estão entre os precursores em explorar esta capacidade tecnológica (hiper-realidade) a partir de um tema; observa-se seu início com a Disneylândia, em 1955 e, posteriormente, chegando aos shoppings centers que se constituem na atração turística de maior importância após a Disney, apresentando exepcional grau de indiferenciação cultural, traço inconfundível da pós-modernidade. São os chamados "não-lugares" para usarmos a expressão de Marc Augé. "É este intercâmbio de signos que torna possível a construção de um pastiche de tema, cada um dos quais se torna mais real do que o 
original, sobretudo devido ao modo como os centros de compras, em geral, enfatizam a novidade, a segurança e a limpeza. Nos shoppings, olhamos e somos olhados como se estivéssemos de férias, ali as compras constituem apenas parte da atração do local que está igualmente voltado para o lazer e turismo", (Shields, 1989: 154).

Sabe-se que a Disneylândia, inaugurada dia 17 de junho de 1955, com ingressos a U\$ 5,00, foi criada para ser um parque de diversões de vanguarda, com atrações fora do comum e extremamente emocionantes. "Será um lugar onde as pessoas encontrarão felicidade e conhecimento. Será um lugar no qual os pais e os filhos partilharão momentos agradáveis, um lugar onde mestres e alunos descobrirão os caminhos abertos da compreensão e da educação. Aí, as gerações dos mais velhos poderão reencontrar a nostalgia dos dias passados, e os mais novos poderão saborear os desafios do futuro. Aí, existirá para todos a possibilidade de compreender as maravilhas da natureza e da humanidade", (Lanquar, 1992). Completa Bob Thomas (1969), usando as palavras de Disney: "A Disneylândia não foi projetada apenas para crianças - e quando uma pessoa deixa de ser criança?. $\mathrm{Eu}$ acredito que o entretenimento apropriado pode agradar a qualquer pessoa, jovem ou idosa...quero que a Disneylândia seja um lugar onde adultos possam trazer seus filhos ou virem sozinhos e, assim mesmo divertirem-se bastante". Segundo afirma Roberto C. de Oliveira (1995) os americanos dizem: "vamos a Disneylândia para sentir que fora dali sua vida é real". O pósmodernismo está ancorado aqui; na insustentável leveza de não crer nem na realidade, nem na ficção.

Outra questão interessante diz respeito à origem dos parques temáticos, já que, segundo algumas teorias, eles teriam existido - antigamente na forma de jardins cuidadosamente elaborados, como fonte de inspiração nas artes, jogos e cultivo de plantas raras, como observaremos no capítulo seguinte com maior ênfase.
Miodrag Mitrasinovic, em sua tese, supervisionada pelo professor Dr. William Tilson, da Universidade da Flórida, identifica e analisa parques temáticos como uma tipologia arquitetônica contemporânea, operando em uma moldura auto-criada e auto-contida em um microcosmo mitológico. Este é compreendido como um território de identidade distinta, gerada pela homogeneidade de seus semióticos: um tema particular narrativo ou visual, os sistemas de ordenação espacial e visual ou sua posição em relação a um molde cultural contemporâneo maior.

O conceito de Miodrag reforça ainda mais as argumentações de Soja pois a cultura e o comércio estão indissoluvelmente interligados em uma proporção cada vez maior dentro da significação (representação e realidade), isto quer dizer que aquilo que consumimos, cada vez mais, são signos ou representações, que são aceitas em um espírito de espetáculo. Em outras palavras, as identidades sociais são construídas por meio da troca de sinais, pois a prática turística sempre envolveu o espetáculo com pouca separação entre a arte e a vida social, pois o que é contemplado é o modelo ideal.

Parques temáticos estão deslocados do cenário urbano, situados geralmente na periferia metropolitana. Não obstante, como observou Edward Soja, o princípio da hiper-realidade foi retirado dos moldes limitados e firmemente unidos pela racionalidade dos parques temáticos para ser introduzido nas geografias e biografias da vida quotidiana, explicando o caráter efêmero das culturas urbanas em geral.

É um conceito que se baseia num tema específico, ilustrado por personagem(s), localizado(s) geralmente em áreas extensas que permitam uma ampla abordagem do tema escolhido, instalação de brinquedos de alta tecnologia e de uma boa infra estrutura para atividades complementares. Trata-se de um local cercado, o que contribui para a segurança de seus freqüentadores, para cujo acesso cobra-se uma tari- 
fa de entrada. Destina-se ao divertimento, entretenimento, contemplação, educação, alimentação (já que passamos muitas horas no local) e compras, utilizado em tempo de lazer, de descanso e de ócio. Trata-se de um espaço lúdico onde jogos, brinquedos e descontração convidam ao divertimento. É planejado de modo que o público permaneça por longo período desfrutando das várias opções e com a certeza e o desejo de repetir a visita.

A definição que a maioria dos analistas adota é a de que parques temáticos são de lazer onde estão distintas atrações criadas a partir de um tema concreto como inspiração ou pano de fundo, presentes em todos os componentes do parque, sejam eles equipamentos, desenhos, arquitetura ou gastronomia.

\subsubsection{Características}

Existem algumas diferenças entre um parque urbano e um parque temático. Segundo Andrés Pan de Soraluce (general manager da Disneyland-Paris para o sudeste da Europa) a Disney, pioneira e líder mundial em parques temáticos, apresenta algumas condições que um estabelecimento deste tipo deva reunir:

- estar composto por atrações exteriores e cada uma deve ser peça independente; atração;

- ter um custo de entrada e não por

- ser construído com base nas necessidades dos visitantes;

- focalizar mais diversão do que aprendizado;

- proporcionar mais sensação física do que simulação;

-e por último, ser um destino em si mesmo.

\subsubsection{Territórios espaciais}

O evento arquitetônico e sua relação com a vivência do parque temático é essencial para a compreensão do mecanismo que determina o seu sucesso macroeconômico.

Dentro de um contexto elaborado para um parque temático, existe uma teia de territórios espaciais. Eles podem ser definidos como:

- lugares para ver;

- lugares para comer;

- lugares para comprar;

- lugares para vivenciar.

Estes territórios, funcionando como sistemas, formam um tecido social (microcosmo) que contribui para identificar o parque temático e para construir a vivência que ele oportuniza.

A oferta de conveniência quando o visitante compra ou come, enfim, consome, caracteriza uma atração dentro da atração. Tendas temáticas são espalhadas por todo o parque de forma aparentemente aleatória e convidam o freqüentador, que em geral está predisposto a levar uma parte da vivência do parque temático consigo para casa, como prova de que o sonho foi realmente vivenciado, na forma de souvenir, fotografias, etc. Os lugares para vivenciar são uma representação dimensional de um acontecimento que marca um ponto específico ao longo de um itinerário temático, que é o que vamos chamar de "jornada", e que se transforma após a entrada e desenvolve-se, permitindo que uma nova noção de "lugar" surja como evento interativo.

O imaginário contemporâneo é fortemente explorado nos parques temáticos. São imagens que trazemos conosco desde a infância, sendo assim, o prazer está no rereconhecimento, ou seja, na identificação daquilo que já sabemos. Por outro lado, o futuro também tem um sabor diferente, são fragmentos de situações projetadas além do cotidiano (fantasias). Segundo Peter Berger, os universos simbólicos ordenam a história, localizando os eventos numa seqüência que inclui o passado, o presente e o futuro. Em relação ao passado estabele- 
cem uma memória, partilhada pelos componentes de uma coletividade; com respeito ao futuro, definem um conjunto de projeções, modelos para as ações individuais. Os universos simbólicos possuem um valor central em todas as sociedades, onde o passado e o presente partilham da mesma dimensão. Assim, Frederic Jameson diz que as sociedades pós-modernas têm uma "nostalgia do presente", ou ainda, ao se deparar com um universo conhecido, sua vida se repete e os objetos se repetem.

\subsubsection{Microcosmo social}

Ao discutir o surgimento e evolução da Disneylândia e do Disney World, Jean Baudrillard argumenta que as pessoas são atraídas pelo microcosmo social e não por um realismo tecnológico super-racionalizado. "Neste mundo imaginário apenas as alegorias da fantasia fazem parte do calor e afeto inerentes às multidões... em contraste com a solidão absoluta dos estacionamentos dos parques temáticos" (Baudrillard, 1981: 137).

O que atrairia as multidões aos parques seria, mais do que qualquer outra coisa, o microcosmo social que, muitas vezes, perder-se-ia nos empreendimentos comerciais convencionais, sem entretanto ter sido completamente eliminado como num gerador potencial de programas públicos para um grande número de pessoas.

Devemos conferir uma enfase especial às aplicações do modelo de determinado parque temático, que surgem através da evolução dos territórios suburbanos dos centros das cidades (amplificados pelo turismo metropolitano), dos shopping centers e dos hotéis do tipo resorts. As palavras de Peter Hall são uma antecipação profética para cuja compreensão é imprescindível conhecer os processos que impulsionam a criação e determinam o comportamento dos parques temáticos.

"A cidade industrial do final do século XIX e começo do século XX, rapidamen- te se transformará em um artefato do passado a ser visitado na forma de um museu a céu aberto como o South Street Seaport de Nova York ou o Distrito das Pedras de Sydney" (Hall, 1991: 89).

Baudrillard contribui com a definição de Hall ao afirmar que os parques temáticos materializam uma utopia atemporal através da produção de eventos distintos simultâneamente, inexorávelmente misturando seqüências vivenciais como se fossem telas e criando uma civilização aparentemente diferente da nossa. Só que, na verdade, ela já se tornou nossa civilização, fazendo com que seja cada vez mais difícil para nós imaginarmos o real, o histórico, o espaço tridimensional passado, assim como uma vez foi difícil imaginar, de nossa perspectiva mundana, um universo virtual ou a quarta dimensão. Segue dizendo:

“... o verdadeiro parque temático ultrapassa o imaginário. Inicialmente, tomava-se o imaginário como sendo realidade virtual, e agora estamos no processo de capturar o mundo real e condensá-lo em um único universo sintético, sob forma de um "show da realidade" onde é a própria realidade que se transforma em espetáculo, onde o real é que vira parque temático ou de diversão. A transfusão do real é como uma transfusão de sangue, exceto que aqui trata-se de uma transfusão de sangue real para um universo de mentira, imaginário, porém inspirado em nossa própria necessidade de perceber o real. Após a prostituição e adulteração do imaginário, agora adotamos a alucinação do real para chegar à sua versão mais simplória e ideal." (Baudrillard, 1997: 124-125)

\subsection{Evolução e história dos parque temáticos}

Criado o conceito, poderemos retomar a história sob novo ponto de vista, ou seja, 
sob o ponto de vista dos parques temáticos. Nestes termos, as raízes históricas dos parques temáticos remontam à Europa medieval (1400-1500), quando jardins meticulosamente trabalhados começaram a aparecer nos arredores das grandes cidades. Estes jardins foram os verdadeiros precursores dos parques temáticos contemporâneos, Embora sem a denominação que hoje utilizamos, apresentavam a oferta de entretenimento, fogos de artifício, danças públicas, músicas e jogos como dama e xadrez. Os chamados jardins do prazer (Jardins du Plaisir) permaneceram populares até meados do século XVIII, quando distúrbios políticos importantes (Revolução Francesa, em especial) causaram o fechamento da maior parte destes parques. Um, no entanto permanece até os dias de hoje: Bakken, ao norte de Copenhagen, aberto em 1583, mundialmente conhecido como o maior e mais antigo parque de divertimento do mundo. No final do século XIX, a crescente industrialização, a reurbanização das grandes cidades e o advento do transporte público de massas, após a guerra civil americana, incrementa a indústria dos parques temáticos nos Estados Unidos da América.

No começo dos anos 50 vimos o surgir da televisão, a decadência urbana, a desagregação social, as lutas raciais, provocando e impedindo o alastramento do conceito de parque de diversões. Mas, à semelhança do que viriam a ser os Beatles na música popular, o mundo viveu no ano de 1955 o grande fenômeno do entretenimento infanto-juvenil: Disney.

Mais do que estabelecer um novo padrão de preferências no divertimento infanto-juvenil, Walt Disney nos traz a denominação, na ampliação de parques de diversões, até então desconhecidos. Destacado e pioneiro em parques temáticos, Disney acreditava piamente no potencial econômico da proposta dos parques temáticos de massa. Quando a Disneylândia abriu suas portas em 1955, os críticos viam esta iniciativa com ceticismo e dúvida. Mas Disney não se preocupou apenas com os brinque- dos, que caracterizavam os conhecidos parques de diversões: criou cinco zonas distintas de visitação, cada qual conduzindo o visitante a um local de fantasia pelo tempo em determinada região do mundo. A Disneylândia, utilizando como tema as histórias do próprio Walt Disney, foi um sucesso fabuloso, também conferido pelo fato de oferecer opções de alimentação e compras dentro do parque. A Disneylândia marca o início de uma nova era no que diz respeito ao turismo mundial, a era dos parques temáticos.

Nos anos que se seguiram, muitas tentativas de abrir novos parques temáticos fracassaram. Apenas em 1961 surgiria o "Six Flags Over Texas", grande e completo suficiente para competir com a Disneylândia. Pois, é justamente em função do tamanho e da complexidade, do custo e principalmente da enorme infra-estrutura exigida, que o número de parques temáticos não cresce muito rapidamente após 1960 . Mas no ano de 1971, onze anos após a inauguração da Disneylândia, Disney inaugura mais um parque temático, o Walt Disney World, desta vez na Flórida, em Orlando, onde o clima é favorável o ano inteiro. Apenas na década de 80, com o advento da informática e com a consolidação de novos megacentros urbanos no mundo todo e, que os parques temáticos ganham popularidade e dimensão internacional.

Em 1982, é inaugurado o EPCOT - Experimental Prototype Community of Tomorrow (Protótipo Experimental da Comunidade do Amanhã), também do grupo Disney, gerando toda uma infra estrutura diferenciada no mundo. Trata-se de um verdadeiro complexo de parques temáticos.

Nos anos 90, os modernos parques temáticos firmam-se na preferência turística mundial, especialmente devido à grande popularização do transporte aéreo, contribuindo destacadamente para a reformulação da infra-estrutura suburbana e trazendo um caráter eclético, universal à cultura do divertimento e do turismo mundial. 


\section{Estudo de caso: "Parque Mini Mundo"}

Em 1956, uma época em que Leopoldo Rosenfeld tanto incentivava o turismo em Gramado, cidade serrana a menos de 120 km de Porto Alegre, Otto e Rita Höppner instalaram na Vila Planalto (bairro próximo ao centro da cidade), um hotel que logo se notabilizou: Hotel Rita Höppner.

Pioneiro e investidor no turismo em Gramado, Otto cria um belíssimo parque infantil, um recanto de turismo e lazer, sem a intenção de ser um estabelecimento comercial mas, como uma maneira de atrair mais turistas ao seu hotel. A cada viagem à Alemanha, trazia novos equipamentos para o "parquinho", transformando o local num excelente atrativo para as crianças da redondeza , fato que logo se espalhou entre a vizinhança e cidades próximas. As constantes visitas das pessoas (adultos e crianças) ao parque, trouxeram a idéia de construir um mini mundo. Já que Otto era construtor e seu filho Heino entendia de eletricidade, a tarefa lhes parecia relativamente fácil. Começaram, então, a pensar num projeto dinâmico, com trens em andamento, navios num porto, teleférico e os mais representativos prédios pertencentes a importantes capitais européias e brasileiras. São construções famosas como o castelo de Neuschwanstein, que custou sete meses de trabalho, a igreja de Stuttgart Berg, a estação ferroviária de Neufen e até a Igreja de S. Francisco de Assis, obra do mestre Aleijadinho, em Ouro Preto. Além destas, encontramos também reproduções de casas típicas alemãs, suíças, finlandesas, teleféricos, pontes, serrarias, moinhos de vento da Holanda, entre tantos outros atrativos que ajudam a compreender melhor as raízes do povo da região das hortênsias.

Outra questão importante, que não deve ser esquecida, é sobre a arquitetura. As réplicas são verdadeiras obras de arte, meticulosamente desenhadas e transferidas para as chapas de acrílico, onde são recortadas em seus menores detalhes arquitetô- nicos que marcaram áureas épocas na história da civilização. Prédios que se conservaram intactos no período de guerras e outros que, totalmente destruídos, foram reconstruídos, podem ser vistos miniaturizados, tão distante de seu lugar de origem.

Sendo batizado de "Mini Mundo", é uma empresa que procura proporcionar a seus visitantes toda a alegria e encantamento que fez parte de seu universo infantil, mostrando um mundo de fantasia: a terra encantada das miniaturas. Em pouco tempo, o parque tornou-se tão conhecido, que passou a ser considerado um passeio obrigatório para quem vai a Gramado.

Otto deixa uma imensa responsabilidade para seu filho e seu neto; a de manter vivo o sonho de um mundo perfeito, iniciado em meados de 1981 e aberto ao público em 15 de dezembro de 1983, sendo também o pioneiro na iluminação natalina em sua cidade miniatura, trazendo inspiração a toda a cidade que hoje comemora o seu tão magnífico e conhecido "Natal Luz".

\section{Conclusã॰ da pesquisa}

Parques Temáticos são planejados e construídos, não são obras do acaso. São o resultado de um conjunto de influências, de tendências sociais e econômicas, de estudos de mercado por parte de pessoas ou grupo de pessoas que pretendem participar da construção do futuro.

O conceito de parques temáticos apresentado nesta pesquisa não deixa dúvidas de que se trata de uma nova tendência no que diz respeito ao turismo no Brasil, e já consagrada nos Estados Unidos e Europa. Usando de alta tecnologia o parque se apropria de um tema específico, algo existente em qualquer parte do mundo ou mesmo em livros, e constrói um ambiente imaginário, baseado numa realidade ou irrealidade. Este ambiente se constitui em uma nova cidade, sem no entanto conter o seu cotidiano. Esta cidade atua como um palco, onde até a alimentação se transforma em 
espetáculo. As compras, a arquitetura, a arte e a cultura, tudo faz parte deste espetáculo, interligando a cultura e o comércio, é onde a imaginação não tem limites pois aqui se explora a hiper-realidade (somente possível com a utilização da tecnologia), que é saboreada por turistas de todas as nacionalidades, buscando um objetivo comum: a diversão, o entretenimento, o ser criança. Sendo que, este último foi exatamente o que Walt Disney tentou reviver em seus visitantes, camuflando-o com cultura, alimentação e compras. São os espaços para o descontrole controlado, onde pais e filhos poderão se divertir juntos, ou seja, adultos e crianças.

O Mini Mundo, por sua vez, não poderia, de forma alguma, ser comparado a uma Disney, embora também seja um parque temático, porém de contemplação. $\mathrm{O}$ objetivo aqui não foi o de comparação, mas sim, o de analisar um produto gaúcho: a que todos temos acesso e talvez a maioria já o conheça e, principalmente, o de resgatar uma cultura que vem sendo preservada. $\mathrm{O}$ que faz do Mini Mundo um verdadeiro parque temático, entretanto, é que ele, à semelhança da Disney, nos transporta a uma outra realidade, a uma outra dimensão, no caso, um mundo de fantasia gerado a partir da contemplação e não da participação ativa. Além da virtualização contemplativa, o Mini Mundo nos permite compreender, imediatamente, o fato de estarmos inseridos numa era pósmoderna, a partir das diferenças e semelhanças que observamos entre nossas cidades e a miniaturização (réplica) da sociedade passada, presente e estrangeira ali representadas e, claramente, vinculadas culturalmente com a cidade de Gramado.

A dimensão urbana da cultura pósmoderna é indissociável da virtualização de nossas fantasias e mitos civilizatórios, e a miniaturização culturalmente idealizada e dirigida, contextualiza urbanísticamente a cidade na qual o Mini Mundo está inserido, transportando os observadores a uma realidade parcialmente virtualizada e ide- al, porém não totalmente dissociada do que eles encontram na realidade que se observa à sua volta em restaurantes, igrejas, lojas e hotéis. Ao observar o Mini Mundo, o visitante virtualiza e realiza sua vida em uma cidade alemã, transformando em realidade suas fantasias ao desfrutar de Gramado como visitante e turista.

O Mini Mundo é, assim, um parque temático, pois as casinhas que o compõem são réplicas (cópias) de casas verdadeiras que ocupam outro espaço, que não o seu de origem, formando uma nova cidade em miniatura e é um parque de contemplação, já que não podemos entrar nos trens ou cantar no coro, ou ainda, entrar nos castelos que estão nesta mini cidade. $\mathrm{O}$ que podemos fazer é observar este trabalho maravilhoso que a família Höppner vem preservando e contribuindo para que a cidade de Gramado não perca esta grande atração turística.

Ao longo deste trabalho, adotei autores dignos de reflexões intermináveis, com a estrita finalidade de esclarecer e conceituar, da maneira mais cristalina possível, várias de nossas interrogações mas, ao congelar todos estes conceitos, transportá-los e aplicá-los no caso brasileiro, recorremos ainda às propostas da Embratur (Empresa Brasileira de Turismo).

Segundo seus dados, "esta indústria (dos parques temáticos) apesar de jovem e ainda pouco numerosa no Brasil, tem demonstrado capacidade de crescimento acelerado nos últimos anos, de um lado por força de uma tendência mundial e, de outro, pelo fortalecimento da atividade, dada a estabilização econômica nacional" (Embratur, 1997).

Acredito que a indústria dos parques temáticos está apenas no início de sua jornada rumo a um futuro muito promissor no Brasil, e mais ainda com a entrada de grupos estrangeiros no setor, nos últimos anos, alguns deles já com parques em funcionamento e outros com planos de investimentos. São alguns indícios de que o setor irá crescer . 


\section{Referências}

http://www.ourinhos.com.br/megatour/htdocs/PAR-

QUES.html\#ini

http://web.nwe.ufl.edu/ miodrag/theme.htm/

http://www.mediaveb-tv.de/dx/rv/56dx0921.html

http://web.nwe.ufl.edu/ miodrag/postland.html

http://www.cac.ufpe.br/actvirt/eventos/mike/mike.htm

http://www.iaapa.org/main.htm

http://www.4adventure.com/

http://www.unet.es/olimpo/e003.htm

http://www.uam.es/www/enlaces/par-tem.html

http://www.inrea.com/stheme.htm

http://www.sync.com.br/parquestk.htm

http:/ /www.riomall.com.br/travelmania/partem.html

http://embratur.gov.br/embratur/est.html

Almeida, Elvira. Arte Lúdica, S. Paulo, FAPESP/EDUSP, s/ data.

Baptista, Mário. Turismo - Competitividade sustentável. Verbo, São Paulo, 1997.

Baudrillard, Jean. A Sociedade de Consumo. Editora 70, Lisboa, 1981.

Baudrillard, Jean. Tela Total. Mito - ironias da era do virtual e da imagem. Sulina, Porto Alegre,1997.

Baudrillard, Jean. Simulacros e Simulações. Relógio D’Agua, Lisboa,1991.

Bell, Daniel. 0 Advento da Sociedade Pós-industrial. Cultrix. São Paulo-SP s/data, título original de 1973.

Certeau, Michel de. A Invenção do Cotidiano - Artes de Fazer. Vozes, Petrópolis, RJ, 1996.
Cerver, Francisco Asensio. Theme and Amusement Parks, N. York, Hearst Books International, 1997.

Eliot, Marc. Walt Disney: O Príncipe Sombrio de Hollywood. Marco Zero, São Paulo-SP,1995.

Eco, Umberto. Viagem na Irrealidade Cotidiana, Rio de Janeiro, Nova Fronteira, 1984.

Featherstone, Mike. Cultura de Consumo e Pós-Modernismo. Nobel, São Paulo, SP, 1995.

Featherstone, Mike, 0 Desmanche da Cultura: Globalização, PósModernismo e Identidade. SESC, Nobel, São Paulo, SP, 1997.

Gastal, Susana e vários autores. Turismo: 9 propostas para um saber fazer. Edição dos Autores, Porto Alegre, 1998.

Goodman, Danny. Vivendo a Velocidade da Luz. Makron Books, São Paulo, 1996.

Hall, Peter. Modelos de Análisis Territorial. Oikos-Tau, Barcelona, 1975.

Hall, Peter. Cidades do Amanhã. Perspectiva, São PauloSP,1995.

Harvey, David. A condição pós-moderna. Loyola, Rio de Janeiro, 1989.

Holden, Robert. Diseño Del Espacio Público Internacional, Barcelona, Gustavo Gili S. A.1996.

Jameson, Fredric. Sementes do Tempo, S. Paulo. Ática, 1997.

Lévy, Pierre. 0 que é virtual?. Editora 34, São Paulo, SP, 1997.

Lyotard, Jean. F. O Pós-Moderno, R. Janeiro, José Olympio, 1986.

Moura, Paulo C. Construindo o Futuro: 0 impacto global do novo paradigma. Mauad, Rio de Janeiro, 1995.

Naisbitt, John e Abuerdene, Patrícia. Megatrends 2000, S. Paulo, Amana, 1990.

Oliveira, Roberto Cardoso. Pós-Modernidade, Campinas, UNICAMP, 1995. 
Ortiz, R. Cultura e Modernidade, S. Paulo, Brasiliense, 1991.

Ortiz, R. Mundialização e Cultura, S. Paulo, Brasiliense, 1996.

Piscitelli, Alejandro. Ciberculturas en la era de las máquinas inteligentes. Paidós, Argentina, 1995.

Ruschmann, Dóris. Turismo e Planejamento Sustentável: A Proteção do Meio Ambiente. Campinas, Papirus, 1997.

Santos, Jair F. dos, 0 que é Pós-Moderno, S. Paulo, Brasiliense, 1997.

Santos, José L. dos, O que é Cultura, S. Paulo, Brasiliense, 1995.

Schnitman, Dora Frie. Nuevos Paradigmas, Cultura y Subjetividad, Buenos Aires, Barcelona y México, Paidós, 1995.

Thomas, Bob. Walt Disney: 0 Mago da Tela. Melhoramentos, São Paulo-SP,1969.

Trigo, Luiz G.G.. Turismo e Qualidade: Tendências Contemporâneas, Campinas, Papirus, 1996.

Trigo, Luiz G.G.. A sociedade pós industrial e o profissional em turismo. Campinas, Papirus,1998.

Urry, John. O Olhar do Turista, S. Paulo. Nobel-SESC, 1996.

Zilles, Urbano. Teoria do Conhecimento, P. Alegre, EDIPUCRS, 1995.

Revista Veja, Turismo, 22 de Abril de 1998, p. 94.

Zero Hora, 13/7/97, Caderno de Economia e Caderno Viagem de $2 / 10 / 1998$.

Gazeta Mercantil, 29 de julho de 1998, "Relatório, Dossiê: Parques Temáticos".

Correio do Povo, 14 de junho de 1998, Caderno de Turismo.

Revista Ícaro, abril de 1998.

Jornal Ad Busines, 1/6/1997.

Jornal do Brasil, 17 de agosto de 1997, Caderno de Economia.

Jornal do Brasil, 17/8/97, pg. 25 e 14/9/97, pg. 12.
Jornal do Brasil, Revista de Domingo, 30/3/1997, Caderno de Viagem, 2/7/1997.

Frommer's Orlando '93, Prentice Hall Travel.

Miami, Insight City Guides, APA Publications.

Hotelnews, setembro/outubro de 1996, pgs. 44, 45, 46 e 48. EMBRATUR

\section{Pesquisas sobre Mini Mundo:}

Jornal de Gramado Especial, 13/05/1979 pg. 19, 13/03/1987 pg. 2, 26/06/1987 pg. 9.

Revista Quatro Rodas, n’ 260, março de 1982.

Zero Hora, Revista ZH, n 150, 09 de janeiro de 1983.

Zero Hora, Revista ZH, página 9,10 e 11, 09/01/1983.

O Estado de São Paulo, Caderno Viagem, 31 de maio de 1994, 19/01/1986.

Jornal do Brasil, Caderno Turismo, página 11, 02 de março de 1983, página 6 de 22/06/1988.

Zero Hora, Revista ZH, p. 23, 14/03/1982, 01/11/1987, 18/ 01/1989 p.18.

Revista Visão, No 17, página 42 e 43, 25 de abril de 1983.

Revista Visão, página 10, 08 de agosto de 1983.

Pioneiro, página 3, 12 de agosto de 1983.

Zero Hora, Segundo Caderno, página 3, 28/07/1983, por Célia Ribeiro 08/03/1985, 30 de março de 1986, 26/09/1986.

Correio do Povo, 29/07/1983.

Correio do Povo, 09/08/1983, página 13 de 02/06/1988.

Revista Cláudia, No 258, página 160.

Revista Manchete, página 144, reportagem de Marina Wodtke.

Revista Criativa, Turismo, outubro de 1982. 
O Estado de São Paulo, suplemento de turismo, 09/11/1982, 13/12/1982, 04/01/1985.

Revista Semanal, Rio de Janeiro, N ${ }^{\circ}$ 1633, ano 31, 06 de agosto de 1983.

Revista Ferroviária, julho de 1986.

Revista Viagem e Turismo, março de1984.

Folha da Tarde, geral, 01 de setembro de 1983.

Pioneiro, 07 /12/1983 e 22/12/1983.

Jornal de Novo Hamburgo, especial turismo, 18/11/1983.

Jornal de São Paulo, suplemento de turismo, 27/01/1984.

O Globo, caderno de turismo, 14/06/1984.

Folha de São Paulo, pg. 10, turismo, 05 de setembro de 1986.

Revista Máxima, nº 35, julho de 1992, página 110 e 111.

Revista Manchete, 20 de maio de 1995.

ABC Turismo, página 6B, 29 de outubro de 1995.

Revista Exame VIP, nº 132, Abril de 1996, pg. 42 e 43.

Revista 0 km, ano i, no 3, junho de 1995.

Pioneiro, caderno de turismo, 26 de junho de 1996.

Gazeta Mercantil, turismo, 26/06/96.

Revista de bordo VASP, $\mathrm{n}^{0}$ 14, 1998.

Jornal de Gramado, 21/02/1997, 07/03/1997, 12/06/1998, 31/07/1998, 07/08/1998, 14/08/1998.

Acervo particular da familia Heino Höppner, fotos com personalidades que visitaram o parque, entrevista concedida especialmente para a realização desta pesquisa, visita ao Mini Mundo e visita na oficina secreta do Sr. Heino. 